\title{
Observations on the Ethical and Social Aspects of Disorders of Consciousness
}

\author{
Eric Racine, Catherine Rodrigue, James L. Bernat, Richard Riopelle, \\ Sam D. Shemie
}

\begin{abstract}
The care of chronically unconscious patients raises vexing medical, ethical, and social questions concerning diagnosis, prognosis, communication with family members, and decision making, including the withdrawal of life support. We provide updates on major controversies surrounding disorders of consciousness. Issues such as withdrawal of artificial nutrition and hydration - which had been considered "settled" by many in the medical, legal and ethical communities - have resurfaced under the pressure of social groups and religious authorities. Some assumptions about the level of awareness and the prognosis of vegetative state and minimal conscious patients are questioned by advances in clinical care because of insights produced by neuroscience research techniques, particularly functional neuroimaging. Both the clinical and neuroscience dimensions of disorders of consciousness raise complex issues such as resource allocation and high levels of diagnostic inaccuracies (at least, for the vegetative state). We conclude by highlighting areas needing further research and collaboration.
\end{abstract}

RÉSUMÉ: Observations sur les aspects éthiques et sociaux des troubles de la conscience. La prise en charge de patients inconscients chronique soulève des questions médicales, éthiques et sociales qui sont éprouvantes en ce qui concerne le diagnostic, le pronostic, la communication avec les membres de la famille et les décisions à prendre, dont le retrait des mesures de maintien en vie. Nous faisons une mise à jour des grandes controverses concernant les troubles de la conscience. Les controverses telles le retrait de la nutrition artificielle et de l'hydratation - qui étaient considérées comme résolues par plusieurs membres des communautés médicale, légale et éthique - ont refait surface sous la pression de groupes sociaux et d'autorités religieuses. Certaines notions au sujet du niveau de conscience et du pronostic de l'état végétatif et les patients minimalement conscients, qui étaient tenues pour acquises, sont remises en question à cause des progrès dans les soins cliniques découlant des techniques de recherche en neurosciences, particulièrement de l'imagerie fonctionnelle. Les dimensions cliniques et neuroscientifiques des troubles de la conscience soulèvent des enjeux complexes tels l'allocation des ressources et le taux élevé d'inexactitudes diagnostiques (du moins pour l'état végétatif). En conclusion, nous soulignons les domaines dans lesquels des recherches et des collaborations plus poussées sont nécessaires.

Can. J. Neurol. Sci. 2010; 37: 758-768

Disorders of consciousness such as coma, the vegetative state (VS), and the minimally conscious state (MCS) are neurological syndromes that disturb awareness or both wakefulness and awareness. Medical advances and neurotechnology have increased the probability of survival for patients suffering from severe neurological injury. Although coma rarely persists more than a few weeks, some patients remain in a VS or a MCS for years. The care of chronically unconscious patients raises vexing medical, ethical, and social questions concerning diagnosis, prognosis, communication with family members, and decision making, including the withdrawal of life support. Our goals here are to update the principal controversies surrounding disorders of consciousness and to discuss how scientific developments and social factors have lead to changes in the ethical landscape of these disorders.

\section{Disorders Of Consciousness}

There has been a longstanding fascination about patients who fail to recover from severe brain injury and remain in a state of

From the Neuroethics Research Unit (ER, CR), Department of Medicine and Department of Social and Preventive Medicine, Université de Montréal; Department of Neurology and Neurosurgery (ER, RR), Biomedical Ethics Unit (ER), Division of Pediatric Critical Care (SDS), Montreal Children's Hospital, McGill University, Montreal, Quebec, Canada; Neurology Department (JLB), Dartmouth-Hitchcock Medical Center, Lebanon, New Hampshire, USA.

Received February 4, 2010. Final Revisions Submitted May 14, 2010. Correspondence to: Eric Racine, Neuroethics Research Unit, Institut de recherches cliniques de Montréal (IRCM), 110 avenue des Pins Ouest, Montréal, Québec, H2W 1R7, Canada. 
unresponsiveness or coma. For centuries, the understanding and diagnosis of disorders of consciousness remained crude and the evidence base thin ${ }^{1}$. Different terminologies and classification systems distinguishing types of comas emerged but the causes of coma (e.g., damage of the ascending reticular activation system or ARAS) remained elusive until the first half of the 20th century. Only then did the role of the ARAS in arousal become apparent ${ }^{2}$. Today, medical, legal, and bioethics discussions rely on the distinction between disorders of consciousness such as coma, the VS, and $\mathrm{MCS}^{3-5}$.

Scientific advances have stimulated a better understanding of the complex mechanisms by which severe brain injury produces disorders of consciousness. The number of patients who survive a brain injury has markedly increased. Nevertheless, our understanding of disorders of consciousness remains incomplete and evolving ${ }^{6}$. Based on the seminal contribution of neurologists Fred Plum and Jerome Posner (The Diagnosis of Stupor and Coma), clinicians consider consciousness a two-dimensional concept defined by the components of wakefulness and awareness ${ }^{3}$. Wakefulness is arousal, the eyes-open readiness of an organism to respond and is different (but essential to) awareness which refers to "the awareness of self and environment" ". Wakefulness and arousal depend on the integrity of the ARAS and its projection to the thalamus while awareness of self and the environment requires a functional thalamus, cortex and their white matter connections ${ }^{3}$. The current classification of disorders of consciousness is clinical and is based on the careful observation and interpretation of clinical signs that support the diagnosis of each syndrome ${ }^{8}$.

Disorders of consciousness should not be conflated with other syndromes. For example, the locked-in syndrome is not a disorder of consciousness but rather a state of profound paralysis caused by pseudobulbar palsy and quadriplegia in which patients can sometimes but not always communicate through limited vertical eye movement and blinking ${ }^{4}$. Another confounding state is akinetic mutism (also called coma vigil) where patients are mute and unable to move. This condition is often caused by lesions to the frontal lobes but patients retain awareness and even the ability to move and speak but are unable to do so. In the early stages, this state can be difficult to distinguish from the vegetative state since patients suffering from akinetic mutism also have sleep-wake cycles ${ }^{4,9}$. Stupor refers to a state in which individuals appear asleep but can be aroused when vigorously stimulated. Stupor can have many causes and can be encountered in different clinical settings. For example, catatonic stupor is a complex symptom combining stupor and behavioral disturbances where patients remain fully conscious as attested by a normal neurological evaluation and recall of events after the stupor episode ${ }^{4,9}$. Finally, brain death is a colloquial term designating death determined by neurological criteria, i.e., death determined by showing the irreversible cessation of all clinical brain functions when breathing and circulation are mechanically supported ${ }^{5}$. This understanding of brain death was captured in initial Canadian brain death guidelines in the mid-1970 $\mathrm{s}^{10-12}$ and has been reaffirmed in the recommendations of a more recent Canadian forum on the neurological determination of death ${ }^{13}$. As a result, there has been widespread implementation of practice standards in Canada and the consistency of performance and documentation of brain death has improved substantially ${ }^{14}$.
Nonetheless, evidence from international studies suggests that institutions lack clear policies for the determination of death and that the use of tests during clinical examination varies ${ }^{15-19}$.

\section{Coma}

Coma derives from the Greek $x \omega \hat{\omega} \mu \alpha$ (koma), meaning deep sleep and is defined as "a state of unresponsiveness in which the patient lies with eyes closed and cannot be aroused to respond appropriately to stimuli even with vigorous stimulation"4. Patients in coma have neither wakefulness nor awareness. They lack sleep-wake cycles and, in the deepest stages of coma, they display no motor responses ${ }^{4,20}$. Coma can result from various brain illnesses and injuries including structural lesions and metabolic/toxic disturbances. Patients' family members sometimes confuse induced coma from barbiturates (e.g., prescribed during neurosurgery or to treat severe status epilepticus) with pathological coma caused by brain injury. Coma rarely lasts more than 30 days in the absence of metabolic, infectious, and toxic complications ${ }^{3}$. Patients suffering from coma can awaken and improve; transit to a VS or MCS, or $\mathrm{die}^{8,21,22}$. The duration of a coma is correlated to the chance of recovery; the longer it is, the poorer the chances of recovery ${ }^{23}$. Recovery depends on factors including site of injury, nature of the damage (trauma, anoxia or other) and the patient's age.

\section{Vegetative state (VS)}

The term "vegetative state" first appeared in 1972 in an article of The Lancet published by Bryan Jennett and Fred Plum $^{24}$. The authors chose the adjective "vegetative" because of its definition in the Oxford English dictionary: "an organic body capable of growth and development but devoid of sensation and thought" 25 . The VS is a state of wakefulness without awareness of self or environment ${ }^{26}$. Wakefulness in the VS is present because of a functional ARAS but awareness is absent because of more extensive damage to the cerebral hemispheres (e.g., diffuse laminar cortical necrosis following acute global hypoxia and ischemia, diffuse axonal injury). Vegetative state patients display sleep-wake cycles unlike comatose patients. Several types of severe damage to the cerebral hemispheres can lead to a VS. The most common causes are traumatic brain injury and hypoxic-ischemic neuronal damage, but a VS can occur as the end-stage of degenerative brain disorders such as Alzheimer although perhaps less frequently than formerly believed ${ }^{3,25}$. In the 1980s and 1990s, expert groups established guidelines for the diagnosis and the management of patients in a VS $22,27-29$ and more recent guidelines have been proposed in the United Kingdom and Australia ${ }^{30,31}$. The earlier guiding statements formulated clinical criteria to establish the absence of selfawareness and the environment such as: the incapacity of interaction with others, the absence of language or understandable expression and the absence of psychological response to stimuli. Any sign of conscious perception or action is incompatible with the diagnosis of a $\mathrm{VS}^{25}$. Usually, VS patients do not require ventilator or cardiac support but require artificial hydration and nutrition ${ }^{32}$. The adjectival terms "persistent" VS (coined to mean present for greater than a month) or "permanent" VS (believed to be irreversible) should be abandoned because they create confusion by confounding diagnosis with prognosis 5 . 


\section{Minimally conscious state (MCS)}

Minimally conscious state is defined as "a condition of severely altered consciousness in which minimal but definite behavioural evidence of self or environmental awareness is demonstrated"20. Minimally conscious state has been defined and approved by a consensus recommendation of the American Academy of Neurology (AAN) in 2002 following the meetings of the Aspen Neurobehavioral Workgroup. Minimally conscious patients distinguish themselves from VS patients "by the presence of behaviors associated with conscious awareness" 20 .

The MCS can result from many causes, such as traumatic brain injury, stroke, degenerative disorders, tumours or neurometabolic diseases ${ }^{20}$. Some patients with major neuronal damage can recover from a chronic state (e.g., coma or VS) but often only with limited responses to stimuli $^{3}$. Although those behaviours do not need to be consistent they must be reproducible or supported long enough to be differentiated from reflexive behaviour. For example, eye blinking must be in response to a specific event. The state of minimal consciousness may be temporary, during the recovery following a brain injury, or permanent. Recovery is hard to predict but chances of improvement appear to decrease over time in $\mathrm{MCS}^{20}$. When patients can reliably and consistently communicate they are considered to have emerged from MCS.

\section{Controversies AND DILEMMAS IN ETHICAL AND SOCIAL ASPECTS OF DISORDERS OF CONSCIOUSNESS}

The care of patients with disorders of consciousness has raised several important ethical and social issues (Figure). Consensus over withdrawal of artificial nutrition and hydration and life support are the topic of ongoing public and religious debates. Other issues are gaining attention because of advances in clinical care or because of insights produced by neuroscience research techniques, particularly functional neuroimaging ${ }^{33-35}$.

\section{New diagnoses and need for international clinical and} ethics guidelines and collaboration

In the 1990s, professional organizations in neurorehabilitation and neurology in the United Kingdom, the United States, and Australia published clinical guidelines clarifying the criteria for the diagnosis and prognosis of VS. Nevertheless, variability and disagreement in these areas remain. For example, the AAN suggested that the diagnosis of persistent VS can be asserted at one month post-injury ${ }^{28}$. The American Congress of Rehabilitation Medicine agreed but recommended that the use of the terms "persistent" and "permanent" not be used to qualify the VS because of the uncertainties related to prognosis and recovery ${ }^{27}$. The International Working Party on the Management of the Vegetative State did not conceptualize the VS as a single entity, rather suggesting that the VS represented a continuum of states (e.g., hyporesponsive state, reflexic responsive state, localizing responsive state, transitional state $)^{29}$.

The acceptance of the diagnosis of MCS in 2002 added an additional layer of complexity to the diagnostic landscape of disorders of consciousness. The Aspen Neurobehavioral Workgroup was convened to resolve the potential confusion and consequences of variability between guidelines. The Aspen Workgroup, like the American Congress of Rehabilitation Medicine, recommended that "persistent" be avoided when describing a VS, and that the diagnosis of VS be accompanied by the cause and duration, post-onset, of the injury ${ }^{36}$. Another source of ongoing discussion is the assessment of visual tracking, blinking in response to perceived threat, and motor responses orientated in response to noxious stimuli. In 2002, the Aspen Workgroup considered a sustained visual fixation as a purposeful movement, therefore a sign of MCS. A year later, in their revised guidelines, the Royal College of Physicians of London, [UK] described fixation as a "compatible but atypical" feature ${ }^{30,37}$.

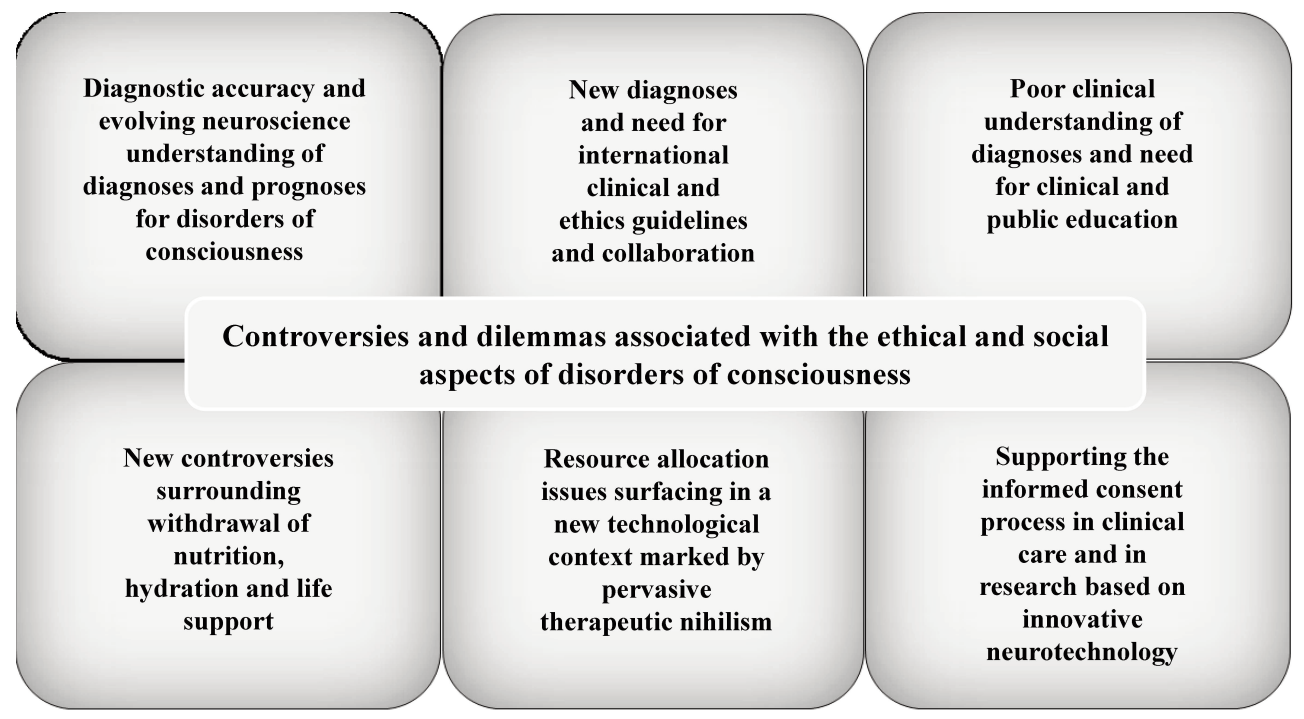

Figure: Controversies and dilemmas in the ethics of care and research with comatose patients 
The Australian Government's National Health and Medical Research Council proposed a substantial shift in approach by advocating terminology describing the unresponsiveness of patients with disorders of consciousness, particularly "post-coma unresponsiveness" to designate a VS and "minimally responsive state" to designate $\mathrm{MCS}^{31}$. The Australian body recommended these changes to exclude conditions that do not follow a state of coma (e.g., terminal stages of Alzheimer's disease), to avoid what some consider pejorative language ("vegetative") and to circumvent time-based qualifiers, which can confuse "persistent VS" with "permanent VS." Some authors have criticized the term MCS because it suggests the existence of some level of consciousness (in the sense of awareness) that is difficult to ascertain. Accordingly, the "minimally responsive state" might be a better clinical term than $\mathrm{MCS}^{7}$.

Further international discussion and consensus could improve clarity in this area of practice ${ }^{37}$. Some discrepancies are minor and should not overshadow broader and more fundamental consensuses. Nonetheless, greater terminological and definitional consistency would help consolidate research and standards of care.

\section{Diagnostic accuracy and the need for professional and public education}

The diagnosis of VS or MCS is possible only after a careful assessment of a patient's level of awareness and responsiveness. However, several potential sources of errors must be avoided. For instance, patients after brain trauma are often unable to speak or move but this impairment does not necessarily mean that they lack awareness. Behavioral assessment, similarly, is not immune from subjectivity. The prevalence of VS is low, estimated at 19 cases per million in a large European city ${ }^{38}$. As a result, physicians in many practice settings may have little experience with these diagnoses. A few studies on diagnostic accuracy for the VS have been published pointing to significant diagnostic inaccuracy in the VS. However, we have little evidence on diagnostic accuracy for MCS.

For example, a study published in 1993 found that $37 \%$ of VS patients had been misdiagnosed because they demonstrated behaviours consistent with cognitive responses ${ }^{39}$. A study on 40 vegetative patients lead by Andrews and his colleagues concluded that $43 \%$ had been misdiagnosed ${ }^{40}$. A more recent report by Schnakers and colleagues suggested that this high level of diagnostic inaccuracy persists today ${ }^{41}$. These studies relied on different strategies to establish diagnosis or evaluate initial diagnoses including retrospective review of diagnosis of patients admitted to a brain injury neurorehabiliation ${ }^{39}$, retrospective study of medical records for patients referred to a neurorehabiliation unit ${ }^{40}$, and a prospective design involving the use of more refined tools like the JFK Coma Recovery ScaleRevised ${ }^{41}$. Nonetheless, their conclusions seem to establish the existence of difficulties of diagnoses for the VS. The causes of confusion and misdiagnosis remain unclear but Gill-Twaites has suggested a series of factors that could be involved such as: (1) differential diagnosis and definitions; (2) the assessor's previous knowledge; (3) the availability for frequent assessment of the patient over time; (4) the tool used to support the diagnosis; (5) inconsistent involvement of family members and caregivers as well as variability in the patient's medical and physical management ${ }^{42}$. Diagnostic inaccuracy also could result from the confusion over disorders of consciousness in the medical community. For example, one study conducted by Youngner and colleagues found that healthcare providers, including physicians involved in decision making as well as staff involved in care but less in decision making such as nurses and residents, conflate the persistent VS with brain death ${ }^{43}$. Such confusion has been found even among neurologists and neurosurgeons $\mathrm{s}^{44}$ and previously discussed in the Canadian contex $\mathrm{t}^{45}$. Previous research and common neurological perspectives on disorders of consciousness do not appear to have fully penetrated general healthcare knowledge and practice. Reasons for this lacuna include lack of general healthcare education about disorders of consciousness, low prevalence of disorders of consciousness, and lack of exposure to this patient population.

In addition to these diagnostic and terminological challenges, clinicians also appear to experience discomfort and distress when they care for unresponsive and vegetative patients. A few studies have revealed how caring for these patients can lead to conflicting emotions, and widely diverging views on their appropriate medical care ${ }^{46,47}$. Thus the challenge of clinical diagnosis clearly indicates the need for education and dissemination of more precise clinical scales. New tools (e.g., the JFK Coma Recovery Scale-Revised) have been developed and refined to address the limitations of the commonly used but crude Glasgow Coma Scale ${ }^{48}$. However, common to the new and previous tools are the ongoing challenges such as the subjective interpretation of the patient's behaviour by the assessor ${ }^{6}$ and, in the case, of the simple and well known Glasgow Coma Scale, variability in application, especially across subspecialties ${ }^{49,50}$.

The need for professional education is reflective of an equally pressing need for broader public education. Studies find a sizeable gap between current expert medical views and public views and that the distinct states of brain death, VS, and coma are not well distinguished by the public ${ }^{51,52}$. A principal reason for confusion is the lack of availability of quality information for the public ${ }^{33}$. For example, in a study of 30 motion pictures created from 1970 to 2004, Wijdicks and collaborators found that coma was usually incorrectly described and misinterpreted. Most (18 out of 30) motion pictures depicted patients who woke up suddenly, even from prolonged coma with intact cognition. The authors found that "all actors except one remained well groomed with normal muscular, tanned appearance" and none of the coma actors were tracheotomized or displayed contractures. Only two out of the 30 motion pictures (Dream Life of Angels and Reversal of Fortune) provided a reasonably accurate depiction of $\mathrm{coma}^{53}$. Definitional difficulties in distinguishing neurological disorders has also been found in the depiction of coma (2001-2005) in American newspapers ${ }^{54}$. Similarly, examining media coverage of the VS in the Terri Schiavo case, one study found important mischaracterizations of this patient's prognosis and behavioral repertoire (e.g., she responds, she reacts) which were clearly inconsistent with her diagnosis of VS. One fifth of the 1141 articles examined contained statements that she might recover after many years in the VS and several strong expressions were used to describe withdrawal of life support (e.g., murder, euthanasia $)^{55}$. Therefore, families of patients and the lay public may become confused about the diagnosis, prognosis, and behavioral repertoire of patients in states of disordered consciousness ${ }^{56}$. 
Both healthcare professionals and the public remain unclear about these conditions. Further, the sizeable challenges in diagnoses, general healthcare providers' common misunderstanding of disorders of consciousness, variability in the use of common clinical scales and tools, and developing specialized literature suggests a stronger role for expert teams constituted by neurologists, critical care physicians, medical ethicists and other specialists $^{40}$. In the Canadian context, inter-institutional collaborations and telemedicine could be avenues to explore.

\section{Evolving neuroscience understanding of diagnoses and prognoses for disorders of consciousness}

Current debates about advances in understanding disorders of consciousness have surfaced, particularly regarding advances in functional neuroimaging and on improving diagnostic and prognostic accuracy ${ }^{33,57}$. Despite the publication of provocative case reports, there is no "magic-bullet" test that can sensitively and specifically determine the presence of consciousness. The elicitation of clinical signs remains the diagnostic standard. However, the accurate evaluation of cognitive function by observing behavioural signs to determine awareness is difficult because patients emerging from unconsciousness may lack the capacity to perform voluntary movements. Functional neuroimaging could therefore provide additive information on cognitive function, notably on the presence, degree and location of residual brain function ${ }^{8}$. It appears possible that over the next several years, functional neuroimaging research will help identify candidates for neurorehabilitation and more favorable prognoses.

Several studies have assessed functional neuroimaging in VS and MCS. Some of the early results questioned common assumptions about the $\mathrm{VS}^{33}$. For example, in a comparative study of severely brain injured MCS and VS patients, Coleman and colleagues found that three out of seven VS patients and two out of five MCS patients showed "significant temporal lobe responses in the low-level auditory contrast" 34 , a task involving a contrast between auditory stimuli and a silence baseline. The authors concluded that "these results provide further evidence that some vegetative patients retain islands of preserved cognitive function and that in the absence of behavioral evidence, functional imaging provides a valuable tool for the assessment team" 34 .

The most discussed report in this regard was published in 2006 by Adrian Owen and colleagues who examined the brain functions of a 23-year-old woman who suffered a severe traumatic brain injury ${ }^{35}$. The clinical diagnosis of VS was established. They then gave her mental imagery tasks such as imagining playing tennis and navigating around her house. Owen and colleagues found that her fMRI brain activation patterns were similar in location to those of normal subjects performing the same tasks" ${ }^{35}$. They concluded that "these results confirm that, despite fulfilling the clinical criteria for a diagnosis of VS, this patient retained the ability to understand spoken commands and to respond to them through her brain activity, rather than through speech or movement" and "confirmed beyond any doubt that she was consciously aware of herself and her surroundings". They envisioned that such patients could perhaps eventually use their "residual cognitive capabilities to communicate their thoughts to those around them by modulating their own neural activity" 35 .
Based on this promising case report, a larger clinical study was undertaken to better assess the proportion of VS and MCS patients who could communicate and improve the reliability of fMRI-based communication methods. This recently-reported study included $23 \mathrm{VS}$ patients and $31 \mathrm{MCS}$ patients with diverse etiologies. It clearly showed that some patients, specifically those with traumatic brain injuries, "were able to modulate their brain activity by generating voluntary, reliable, and repeatable blood-oxygenated-level-dependent responses" when they were prompted to conduct mental imagery tasks ${ }^{58}$. For two of these five patients, further clinical examination was unable to identify reliable responsive behavior. These observations therefore suggest that a dissociation can occur between, on the one hand, best attempts to identify meaningful behavior through bedside examination and, on the other hand, fMRI-based detection of voluntary and specific response.

Given these results, it is probable that functional neuroimaging will contribute to improving diagnoses even though there are a number of issues that need closer attention before such promise can be delivered beyond the use of fMRI as a research tool. One of the key challenges concerns the acquisition and interpretation of the data yielded by functional neuroimaging and, in particular, its ability to reveal reliably signs of consciousness in response to simple tasks ${ }^{59}$. The diagnostic potential and basic insights generated by neuroimaging tools will likely also be refined with the use of multiple imaging modalities ${ }^{60}$. For example, the combination of techniques like MRI with magnetic resonance spectroscopy (MRS) with diffusion tensor imaging is an interesting development. Magnetic resonance spectroscopy allows to quantity chemical compounds or metabolites related to neuronal integrity and neuronal energetic function while diffusion tensor imaging allows assessing the integrity of white matter. These techniques or the combination these techniques could lead to more precise measures of brain injury, potential for recovery, and response to treatments ${ }^{61-65}$.

In contrast to the excitement surrounding the promises of new diagnostic tools, current treatments of VS patients remain primarily supportive and rehabilitative. Specific stimulation therapies have been attempted but rarely induce awareness ${ }^{3}$. While reports of a few individual patients or small uncontrolled series of treated patients claim improvement in awareness, a meta-analysis of studies of physical and environmental stimulation, deep-brain electrical stimulation, and pharmacological stimulation of VS patients showed no unequivocal effect of any therapy on improving awareness ${ }^{66}$.

Treatment of MCS patients is more encouraging because brain regions in the medial thalamus that have not been as badly damaged as in VS patients may retain the capacity to be stimulated by medications or deep-brain electrical stimuli ${ }^{67}$. Stimulant drugs, particularly those that can enhance intact dopamine neurons in the thalamus, can improve awareness and responsiveness in some MCS patients ${ }^{68}$. The drug zolpidem was reported to "awaken" some MCS patients to greater responsiveness and speech, though the mechanism remains speculative $^{69}$. Deep-brain electrical stimulation of the intralaminar thalamic nuclei performed in one man in a stable MCS for six years induced significant improvement in responsiveness, arousal, and speech ${ }^{60}$. Although encouraging, 
these clinical trials are first steps in the development of treatments for VS and MCS patients.

\section{Supporting the informed consent process in clinical care and in research based on innovative neurotechnology}

In clinical care

Respect for patient autonomy is an essential ethical principle in contemporary medicine and ethics and is well established in Canadian health law and policy ${ }^{70}$. In the landmark case of Nancy B., who suffered from Guillain-Barré syndrome, the Quebec Superior Court ruled in 1992 that a competent patient could refuse life-sustaining treatments and that a physician would not be criminally liable for doing so. In 1990, in a case involving a patient (Mrs. Mallette, a Jehovah's Witness) refusing blood transfusions, the Ontario Court of Appeal judged similarly that the wishes of a patient should be respected even if these would lead to death ${ }^{71}$. The Canadian Medical Association (CMA) has upheld in a policy statement that, "the right to accept or reject any treatment or procedure ultimately resides with the patient or appropriate proxy. This includes the right to accept or refuse resuscitative as well as other life-saving or sustaining measures should they become medically indicated." The CMA specifies that this applies to resuscitative measures but the CMA also clarifies that advance directives cannot be honored under all circumstances because the realities of medical practice make this impossible $^{70,72}$. The Canadian Critical Care Society has adopted a similar position to the CMA regarding consent for end-of-life care in a more elaborate position paper $^{73}$.

It is therefore fundamental for both ethical and legal reasons to support the informed consent process and to ensure that medical decisions are consistent with previously expressed wishes. In the absence of such declarations, decision making must be consistent with the best interests of the patient. However, because patients with disorders of consciousness are unaware and cannot communicate, they cannot directly participate in decision making. In the Canadian context, if patients have written advance directives, these should be respected and guide decisions although provincial variability may impact the scope and application of advance directives ${ }^{71,74,75}$. However, because many victims of traumatic brain injury are young, or the injury is a result of an unanticipated event, it is common for patients not to have documented preferences for life-sustaining treatment. In addition, the interpretation of advance directives is challenging because of the ambiguity of them and because of the discomfort of many healthcare providers in making assumptions about subjective judgments concerning quality of life ${ }^{76,77}$. In the absence of advance directives when the patient is incapacitated, decision-making authority usually is delegated to family members ${ }^{75}$. When this occurs, there are three basic surrogate (proxy) decision-making models that respect the autonomy and preferences of a patient as well as the patient's wellbeing in absence of decision-making capacity (Box 1). Ethics committees can provide advice in unclear cases ${ }^{78}$ and the need for more formal mechanisms like the appointment of legal guardians may help resolve difficult cases where no agreement can be reached within family members or between family members and the healthcare team ${ }^{75}$.
Box 1: Three standards for surrogate decision making based on Eisenberg ${ }^{79}$ and Beauchamp and Childress ${ }^{80}$

First approach: Pure autonomy standard and advance directives

First and foremost, prior autonomous judgments should be accepted. This pure autonomy standard applies exclusively to formerly autonomous, now-incompetent patients who expressed a relevant autonomous preference.

Second approach (if first approach is not applicable): Substituted judgment standard

If there are no advance directives or there is one but the instructions therein do not seem to cover the situation presented, and the patient previously has otherwise made known his or her preferences and values (for example, through conversations with friends and family members), the surrogate makes a decision based on the patient's predicted wishes, attempting to decide as the patient would have decided when competent. Substituted judgment should be used for once-competent patients only if reason exists to believe that a decision can be made as the patient would have made it.

Third approach (if second approach is not applicable): Best interests standard

If nothing or little is known about the patient's preference and values, the surrogate makes a decision based on an assessment of the patient's best interests. The surrogate attempts to determine the highest net benefit among the available options, assigning different weights to interests the patient has in each option and discounting or subtracting inherent risks.

\section{In clinical research}

The participation of patients with disorders of consciousness in research protocols involving functional neuroimaging procedures, drugs, and neurostimulation also raises the vexing issue of patient or proxy consent and the consideration of the patient's preferences and best interests ${ }^{33,81,82}$. The potential volunteer previously might have written advance directives specifically for research participation (a research living will or research advance directive) to provide guidance on his or her prior wishes. These preferences might be to consent to participate in minimal risk research only; refuse to participate to research involving certain procedures; participate in protocols with higher than minimal risk research. In such a case, a pure autonomy standard, i.e., precedence of previously expressed judgments of the volunteer should apply.

In the much more common circumstance in which there are no specific directives for research participation, the volunteer may have designated, through a durable power of attorney, a proxy decision maker (sometimes called a research agent) empowered to make research participation decisions. The decision would lie in the hands of this formally designated research proxy decision maker based on the wishes of the volunteer and applicable legal provisions of the jurisdiction. 
Most often, however, the potential volunteer will not have executed advance directives for research purposes or have formally designated through a durable power of attorney a proxy decision maker for such decisions. In this more common scenario, practices vary depending on the circumstances and the applicable legal and regulatory context. An existing healthcare power of attorney could serve as a research decision maker. A legal guardian may be court-appointed as the legally authorized representative or an informal decision maker (typically from the volunteer's family) may give consent for research participation. Close collaboration with the institutional research ethics board responsible for the approval of the research protocol is strongly recommended beyond the initial approval of the protocol. Following any of these options, the proxy decision maker should respect the previous wishes of the volunteer or otherwise, when clear wishes are unknown, use the best interest standard, i.e., judge, based on the values and prior wishes of the volunteer, what is in his or her best interests. During discussions with the family, any confusion between informed consent for care and informed consent for research should be avoided and addressed $^{82}$. However, the mere incapacity to consent should not systematically exclude these patients from research. Research participation can be justified and ethical if consent by proxy is obtained (and a proper proxy decision-making mechanism identified) and approval by a research ethics board is granted..$^{33}$

Common to the context of proxy decision making in clinical and research context is the underlying need for more frequent use of advanced directives. In addition, the specificity of directives could be enhanced, for example, if pre-made advance directive forms featured various clinical and research scenarios to simplify decisions for patients (and families). While these measures would help, they would not solve all issues or replace sensitive clinical approaches. Finally, a challenging scenario is likely to surface if greater confidence is acquired in the capacity to establish forms of communication with patients diagnosed as being in VS and MCS as reported in recent functional neuroimaging studies ${ }^{58}$ : what would be the clinical and technical criteria to establish the capacity of these patients to communicate reliably their preferences for research participation or clinical care through modalities like fMRI when they remain largely unresponsive?

\section{New controversies surrounding withdrawal of nutrition, hydration, and life support}

Vegetative state and MCS patients retain autonomic functions because of their preserved brainstem functions but need various levels of medical support to stay alive. Sometimes, the only treatment needed is artificial hydration and nutrition because of the incapacity of patients to swallow ${ }^{83}$. In the hope of recovery, patients can be supported over months and even years but over time, chances of recovery diminish. The issues of withdrawing life-sustaining treatment and writing do-not-resuscitate orders often arise.

The CMA, the AAN, and several other medical organizations have opined that artificial nutrition and hydration should be considered a treatment, like other medical treatments, for which a proxy decision maker can consent or refuse ${ }^{84,85}$. For example, the code of ethics of the CMA specifies to physicians that they should "ascertain wherever possible and recognize [the] patient's wishes about the initiation, continuation or cessation of lifesustaining treatment"72. Accordingly, once a diagnosis and a prognosis are reliably confirmed, and the previous wishes of patient are known (see section above on informed consent), patients can be treated aggressively or life-sustaining therapy can be withheld or withdrawn to allow the patient to die if this would have been their wish ${ }^{3}$.

In Canada and the United States, the medical, legal, and ethical consensus accepting withdrawal or withholding of life support were developed based on precedent-setting medicolegal cases of patients with disorders of consciousness, especially Karen Quinlan and Nancy Cruzan ${ }^{86}$. However, recent public debates and some religious groups, notably in the US and Italy, have called into question past expert medical, scientific, legal and ethical consensuses. This trend was visible in the Schiavo case where large-scale political and legal activities were sparked by debates over the removal of her feeding tube in the US ${ }^{87}$. Similarly, in Italy, the case of Eluana Englaro, who was in a chronic state of VS, has provoked passionate debates and involvements of courts, pro-life groups, and reactions from the Catholic Church (Box 2).

Pope John Paul II issued an opinion in 2004 that appeared to contradict the previous Roman Catholic doctrinal acceptance of withdrawal of life support. In a joint statement of the World Medical Association of Catholic Medical Associations and the Pontifical Academy for Life presented at the International Congress on "Life sustaining treatments and vegetative state: Scientific advances and ethical dilemmas," withdrawal of life support was equated to euthanasia and therefore condemned: "[t]he possible decision of withdrawing nutrition and hydration, necessarily administered to VS patients in an assisted way, is followed inevitably by the patients' death as a direct consequence. Therefore, it has to be considered a genuine act of euthanasia by omission, which is morally unacceptable." ${ }^{89}$. In his address to the participants of this congress, the Pope declared that " $[\mathrm{t}]$ he administration of water and food, even when provided by artificial means, always represents a natural means of preserving life, not a medical act. Its use, furthermore, should be considered, in principle, ordinary and proportionate, and as such morally obligatory, insofar as and until it is seen to have attained its proper finality, which in the present case consists in providing nourishment to the patient and alleviation of his suffering. (...) The evaluation of probabilities, founded on waning hopes for recovery when the vegetative state is prolonged beyond a year, cannot ethically justify the cessation or interruption of minimal care for the patient, including nutrition and hydration"

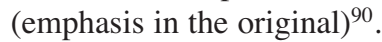

This strong endorsement of the sanctity of life and public reactions to the Schiavo case triggered some American states to re-examine legislation allowing proxy decision makers to withdraw artificial hydration and nutrition from unconscious patients without formal advance directives. In the past few years, some advocacy groups have become more vocal and, consequently, withdrawal of life support remains a source of discord in the public domain. In response to conservative positions, the AAN has reiterated its position regarding the acceptability of withdrawal of life support based on the three standards described in Box 1 (pure autonomy, substituted judgment, and best interests $)^{84}$. In Canada, the Surrogate Court 


\section{Box 2: Controversial publicized cases of patients with disorders of consciousness}

Karen Quinlan (1954-1985): American female patient who fell into a coma after drug use in 1975 . Her parents requested that mechanical ventilation be discontinued by the hospital to allow her to die, which the hospital refused. After a court decision of the New Jersey Supreme Court in favor of the parents in 1976, Quinlan lived in a vegetative state until dying from pneumonia on June 13, 1986.

Nancy Cruzan (1957-1990): American female patient who entered a vegetative state after an automobile accident in 1983. Her family petitioned in courts for three years, as far as the U.S. Supreme Court, to have her feeding tube removed. The family's request was ultimately granted. Her feeding tube was removed December 14, 1990 and she died on December 26.

Terri (Theresa) Schiavo (1963-2005): American female patient who suffered hypoxic-ischemic brain damage during cardiac arrest in 1990 and entered a vegetative state. Her husband Michael Schiavo fought to have her feeding tube removed in opposition to Terri Schiavo's parents (Robert and Mary Schindler). Her case became a national political and political controversy and the object of a controversial law ("Terri's law") of the Florida legislature preventing the removal of her feeding tube. This law was judged unconstitutional by the Florida Supreme Court and her life support was withdrawn on March 18, 2005 and she died on March 31.

Eluana Englaro (1970-2008): Italian female patient who entered a vegetative state on January 18, 1992, following a car accident. The request of her father to remove her feeding tube led to subsequent court disputes and public debate. Following the decision of the Supreme Court to agree to her father's request, she died on February 9th, 2009, four days after the removal of her feeding tube.

Sources: Pence $(2004)^{86}$, Perry, Chuchill, Kirschner $(2005)^{87}$, and Striano, Bifulco, Servillo (2009) $)^{88}$

of Alberta has ruled in 2005 that the sanctity of life is not an overriding value in the determination of appropriate care for a patient in a vegetative state and that maintaining a patient in a VS is not a benefit to the patient ${ }^{75}$.

The question of a patient's quality of life surfaces in discussions and decisions to withhold or withdraw life sustaining treatments for patients with poor prognoses. Views on the moral relevance and practical utility of "quality of life" in medical and ethical discussions vary greatly. Many scholars have emphasized the risks of speculating about a patient's quality of life given the subjective nature of assessing what is a good life and a life "worth living" 91,92 . Other criticisms of quality of life include that perceptions of quality of life may change over time and that studies have demonstrated that healthcare professionals generally tend to underestimate a patient's quality of life ${ }^{80}$. Nonetheless, some have attempted to distinguish between the "objective" and "subjective" factors in assessing quality of life $\mathrm{e}^{92}$. In this scheme, objective factors include social support, employment and ability to communicate with others while subjective factors are defined by the patient her- or himself ${ }^{92}$. Despite the controversies surrounding quality of life, the need to assess the potential beneficial effects of treatments needs to be assessed by clinicians and cannot be dismissed even though the concept of quality of life remains controversial. Efforts should be made to disentangle the medical goals of treatments (and outcomes) from the more subjective assessment of these goals and outcomes in order to avoid providers (and family members) imposing or projecting personal views on a patient ${ }^{93}$. The concept of shared decision making captures this collaborative approach where the respective expertise and experience of providers and family members join forces to reach respectful and mutually acceptable decisions ${ }^{93}$.

\section{Longstanding resource allocation issues resurface in a new technological context marked by pervasive therapeutic nihilism}

Although some patients with disorders of consciousness require minimally invasive care, the services required may consume considerable human and financial resources ${ }^{25}$. In 1994, the Multi-Society Task Force estimated that the total annual cost of adults and children in a VS, in the United States, was between $\$ 1$ and $\$ 7$ billion $^{94}$. It can be assumed that, 16 years later, costs have increased. Healthcare cost and use of scarce acute care resources is an important consideration in most countries, and is an often unspoken factor in end-of-life decisions and the care of patients on life support. The principle of justice requires that vulnerable patients, such as brain damaged patients, be treated equally and no differently than healthy individuals or patients suffering from other conditions $\mathrm{s}^{32}$. The principle of justice also refers to equity, in that the decisions that are taken have to be fair to other patients and society, an issue that has not been extensively discussed ${ }^{95}$. Accordingly, physicians and healthcare professionals may have to consider the benefit that a treatment can bring to a patient as well as to other patients ${ }^{96}$. Several authors and commentators have argued that if a treatment is considered futile for a patient, i.e., that there is less than a $1 \%$ chance of physiological benefit, then it is not unethical to use otherwise unavailable resources for another patient that would directly benefit from them ${ }^{96}$. (Medical futility is often defined as the situation in which a therapy that is hoped to benefit a patient's medical condition will predictably not do so on the basis of the best available evidence ${ }^{32}$.) Wide agreement on such sensitive issues is unlikely to be achieved soon but institutions would benefit from having clearer policies to guide clinicians facing such difficult decisions.

Other challenges created by the management of scarce resources include situations in which patients are transferred from acute care hospitals to long-term and rehabilitation centers because of financial or other pressures. The transfer of patients between institutions can affect the patient insofar as the vision of healthcare professionals (e.g., curative, palliative) may differ from one institution to another. In addition recovery can take many months and long-term care facilities need to be tooled to identify patients that need additional services and resources ${ }^{81,97}$. 


\section{Conclusion}

Both the clinical and neuroscience dimensions of disorders of consciousness are complicated by vexing issues such as resource allocation and high levels of diagnostic inaccuracies (at least, for the VS). Other issues, like withdrawal of life-support, which had been considered "settled" by many in the medical, legal and ethical communities now have resurfaced under the pressure of

Table: Areas for further research, policy and action in care and research for disorders of consciousness

\section{Further research on diagnosis and prognosis}

Develop fundamental and applied interdisciplinary research to increase the evidence base on diagnosis and prognosis. This implies sidestepping "therapeutic nihilism" and existing biases against this patient population to develop and fund research across different institutions.

\section{Promoting ongoing clinical education}

Develop and assess institutional and professional educational programs on clinical aspects of disorders of consciousness and associated ethical challenges. This will become increasingly important with predictable changes to diagnoses and prognoses based on the use of new treatment strategies and new diagnostic tools.

\section{Developing bottom-up research}

Better understand the experience of healthcare providers and family members. Too often the experience of healthcare professionals is unvoiced and is not fully considered in the treatment of chronically unresponsive patients.

\section{Communication and public understanding}

Better identify and characterize common challenges in matters of healthcare communication and also develop strategies to tackle potential miscommunications and sources of misunderstandings. To better prepare difficult discussions with families, research is needed to help identify and characterize potential zones of tensions as well as approaches that can be employed by clinical teams and that could have a broader health policy application.

\section{Shared decision-making}

Develop tools and approaches to support shared decision-making and ensure respect for the patient and family members. Experiences with proxy decision-making and the interpretation of advance directives need to be gathered and shared to better understand the complexities of these situations and the different challenging aspects of this process.

Understanding prevalence, burden, and neuroepidemiology

Better understand the incidence of disorders of consciousness as well as patient and family needs in matters of acute and long-term care. The burden of disorders of consciousness is not well characterized and better understanding the prevalence and medico-social impact would help tailor acute interventions, long-term care needs and programs as well as long term support for families and caregivers.

\section{Developing international collaboration and dialogue}

Ensure greater consistency between different practice communities at local, national, and international levels in matters of care, terminology, and communication. Crosstalk between different professional societies and interested parties is necessary to consolidate perspectives and develop a solid basis for interdisciplinary and international research. social groups and religious authorities. Developments in scientific understanding of the MCS and the VS may gradually alter some assumptions about the level of awareness and the prognosis of VS and MCS patients. These advances, which are tricky to interpret, and the hope and expectations they nourish in families and the public will need to be addressed concretely at the bedside. We identified several areas ripe for further interdisciplinary medical research on the ethical and social aspects of disorders of consciousness. We suggest a need for a broad research and policy agenda that would shed more light on the scientific, medical, social, and ethical landscape of disorders of consciousness (Table).

\section{ACKNOWLEDGEMENTS}

The authors thank members of the Neuroethics Research Unit for early feedback on this paper as well as members of the trilateral neuroethics initiative and participants to the first annual meeting of this tri-lateral group. This work is supported by grants from the CIHR (Tri-lateral neuroethics initiative; New Investigator Award), and the FRSQ (Eric Racine).

\section{REFERENCES}

1. Koehler PJ, Wijdicks EF. Historical study of coma: looking back through medical and neurological texts. Brain. 2008;131(Pt 3): 877-89.

2. Moruzzi G, Magoun HW. Brain stem reticular formation and activation of the EEG. Electroencephalogr Clin Neurophysiol. 1949;1(4):455-73.

3. Bernat JL. Chronic disorders of consciousness. Lancet. 2006;367 (9517):1181-92.

4. Posner JB, Saper CB, Schiff ND, Plum F. Plum and Posner's diagnosis of stupor and coma. 4th ed. New York: Oxford University Press; 2007.

5. Bernat JL. Ethical issues in neurology. 3rd ed. Philadephia: Lippincott Williams and Wilkins; 2008.

6. Shiel A, Gelling L, Wilson B, Coleman M, Pickard JD. Difficulties in diagnosing the vegetative state. Br J Neurosurg. 2004;18(1): $5-7$.

7. Bernat JL. Chronic consciousness disorders. Annu Rev Med. 2009; 60:381-92.

8. Laureys S, Owen AM, Schiff ND. Brain function in coma, vegetative state, and related disorders. Lancet Neurol. 2004;3(9): 537-46.

9. Cartlidge N. States related to or confused with coma. J Neurol Neurosurg Psychiatry. 2001;71 Suppl 1:i18-9.

10. Canadian Medical Association. Guidelines for the diagnosis of brain death. CMAJ. 1987;136(2):200A-B.

11. Patel YC, Ezzat S, Chik CL, et al. Guidelines for the diagnosis and treatment of acromegaly: a Canadian perspective. Clin Invest Med. 2000;23(3):172-87.

12. Lazar NM, Shemie SD, Webster GC, Dickens BM. Bioethics for clinicians: 24. Brain death. CMAJ. 2001;164(6):833-6.

13. Shemie SD, Doig C, Dickens B, et al. Severe brain injury to neurological determination of death: Canadian forum recommendations. CMAJ. 2006;174(6):S1-13.

14. Barrington Research Group Inc. for the Summative Evaluation Steering of the Committee: Canadian Council for Donation and Transplantation. Canadian Council for Donation and Transplantation (CCDT) summative evaluation final report. Calgary: Canadian Council for Donation and Transplantation; 2006.

15. Rocker GM, Cook DJ, Shemie SD. Practice variation in end of life care in the ICU: implications for patients with severe brain injury. Can J Anaesth. 2006;53(8):814-9.

16. Hornby K, Shemie SD, Teitelbaum J, Doig C. Variability in hospital-based brain death guidelines in Canada. Can J Anaesth. 2006;53(6):613-9. 
17. Doig CJ, Young K, Teitelbaum J, Shemie SD. Brief survey: determining brain death in Canadian intensive care units. Can J Anaesth. 2006;53(6):609-12.

18. Powner DJ, Hernandez M, Rives TE. Variability among hospital policies for determining brain death in adults. Crit Care Med. 2004;32(6):1284-8.

19. Greer DM, Varelas PN, Haque S, Wijdicks EF. Variability of brain death determination guidelines in leading US neurologic institutions. Neurology. 2008;70(4):284-9.

20. Giacino JT, Ashwal S, Childs N, et al. The minimally conscious state: definition and diagnostic criteria. Neurology. 2002;58(3): 349-53.

21. Stevens RD, Bhardwaj A. Approach to the comatose patient. Crit Care Med. 2006;34(1):31-41.

22. The Multi-Society Task Force on PVS. Medical aspects of the persistent vegetative state (1). N Engl J Med. 1994;330(21): 1499-508

23. Bates D. The prognosis of medical coma. J Neurol Neurosurg Psychiatry. 2001;71 Suppl 1:3

24. Jennett B, Plum F. Persistent vegetative state after brain damage. A syndrome in search of a name. Lancet. 1972;1(7753):734-7.

25. Zeman A. Persistent vegetative state. Lancet. 1997;350(9080): 795-9.

26. Jennett B. The vegetative state: medical facts, ethical and legal dilemmas. Cambridge: Cambridge University Press; 2002.

27. American Congress of Rehabilitation Medicine. Recommendations for use of uniform nomenclature pertinent to patients with severe alterations in consciousness. Arch Phys Med Rehabil. 1995;76 (2):205-9.

28. The Quality Standards Subcommittee of the American Academy of Neurology. Practice parameters: assessment and management of patients in the persistent vegetative state (summary statement). Neurology. 1995;45(5):1015-8.

29. Andrews K. International Working Party on the management of the vegetative state: summary report. Brain Inj. 1996;10(11): 797-806.

30. Royal College of Physicians. The vegetative state: guidance on diagnosis and management. London: Royal College of Physicians; 2003.

31. National Health and Medical Research Council. Post-coma unresponsiveness and minimally responsive state: a guide for families and carers of people with profound brain damage. Canberra: Government of Australia; 2008. p. 31.

32. Laureys S. Science and society: death, unconsciousness and the brain. Nat Rev Neurosci. 2005;6(11):899-909.

33. Fins JJ, Illes J, Bernat JL, Hirsch J, Laureys S, Murphy E. Neuroimaging and disorders of consciousness: envisioning an ethical research agenda. Am J Bioeth. 2008;8(9):3-12.

34. Coleman MR, Rodd JM, Davis MH, et al. Do vegetative patients retain aspects of language comprehension? Evidence from fMRI. Brain. 2007;130(Pt 10):2494-507.

35. Owen AM, Coleman MR, Boly M, Davis MH, Laureys S, Pickard JD. Detecting awareness in the vegetative state. Science. 2006; 313(5792):1402.

36. Giacino J, Whyte J. The vegetative and minimally conscious states: current knowledge and remaining questions. J Head Trauma Rehabil. 2005;20(1):30-50

37. Laureys $\mathrm{S}$, Boly $\mathrm{M}$. What is it like to be vegetative or minimally conscious? Curr Opin Neurol. 2007;20(6):609-13.

38. Stepan C, Haidinger G, Binder H. Prevalence of persistent vegetative state/apallic syndrome in Vienna. Eur J Neurol. 2004; 11(7):461-6.

39. Childs NL, Mercer WN, Childs HW. Accuracy of diagnosis of persistent vegetative state. Neurology. 1993;43(8):1465-7.

40. Andrews K, Murphy L, Munday R, Littlewood C. Misdiagnosis of the vegetative state: retrospective study in a rehabilitation unit. BMJ. 1996;313(7048):13-6.

41. Schnakers C, Vanhaudenhuyse A, Giacino J, et al. Diagnostic accuracy of the vegetative and minimally conscious state: clinical consensus versus standardized neurobehavioral assessment. BMC Neurol. 2009;9:35.
42. Gill-Thwaites H. Lotteries, loopholes and luck: misdiagnosis in the vegetative state patient. Brain Inj. 2006;20(13-14):1321-8

43. Youngner SJ, Landefeld CS, Coulton CJ, Juknialis BW, Leary M. Brain death and organ retrieval. A cross-sectional survey of knowledge and concepts among health professionals. JAMA. 1989;261(15):2205-10.

44. Tomlinson T. Misunderstanding death on a respirator. Bioethics. 1990;4(3):253-64.

45. Young B, Blume W, Lynch A. Brain death and the persistent vegetative state: similarities and contrasts. Can J Neurol Sci. 1989;16(4):388-93.

46. Montagnino BA, Ethier AM. The experiences of pediatric nurses caring for children in a persistent vegetative state. Pediatr Crit Care Med. 2007;8(5):440-6.

47. Bell TN. Nurses' attitudes in caring for the comatose head-injured patient. J Neurosci Nurs. 1986;18(5):279-89.

48. Kalmar K, Giacino JT. The JFK coma recovery scale-revised. Neuropsychol Rehabil. 2005;15(3-4):454-60.

49. Crossman J, Bankes M, Bhan A, Crockard HA. The Glasgow coma score: reliable evidence? Injury. 1998;29(6):435-7.

50. Buechler CM, Blostein PA, Koestner A, Hurt K, Schaars M, McKernan J. Variation among trauma centers' calculation of Glasgow coma scale score: results of a national survey. $\mathrm{J}$ Trauma. 1998;45(3):429-32.

51. Shanteau J, Linin K. Subjective meaning of terms used in organ donation: analysis of word associations. In: Shanteau J, Harris, $\mathrm{R}$, editors. Organ donation and transplantation: psychological and behavioral factors. Washington: American Psychological Association; 1990. p. 37-49.

52. Siminoff LA, Burant C, Youngner SJ. Death and organ procurement: public beliefs and attitudes. Kennedy Inst Ethics J. 2004;14(3):217-34.

53. Wijdicks EF, Wijdicks CA. The portrayal of coma in contemporary motion pictures. Neurology. 2006;66(9):1300-3.

54. Wijdicks EF, Wijdicks MF. Coverage of coma in headlines of US newspapers from 2001 through 2005. Mayo Clin Proc. 2006;81 (10): 1332-6

55. Racine E, Amaram R, Seidler M, Karczewska M, Illes J. Media coverage of the persistent vegetative state and end-of-life decision-making. Neurology. 2008;71(13):1027-32.

56. Macdonald ME, Liben S, Carnevale FA, Cohen SR. Signs of life and signs of death: brain death and other mixed messages at the end of life. J Child Health Care. 2008;12(2):92-105.

57. Gofton TE, Chouinard PA, Young GB, et al. Functional MRI study of the primary somatosensory cortex in comatose survivors of cardiac arrest. Exp Neurol. 2009;217(2):320-7.

58. Monti MM, Vanhaudenhuyse A, Coleman MR, et al. Willful modulation of brain activity in disorders of consciousness. N Engl J Med. 362(7):579-89.

59. Racine E, Bell E. Clinical and public translation of neuroimaging research in disorders of consciousness challenges current diagnostic and public understanding paradigms. Am J Bioeth. 2008;8(9):13-5; discussion W1-3.

60. Schiff ND, Giacino JT, Kalmar K, et al. Behavioural improvements with thalamic stimulation after severe traumatic brain injury. Nature. 2007:448(7153):600-3

61. Machado C, Rodriguez R, Carballo M, Perez J, Korein J. Results of proton MRS studies in PVS and MCS patients. Can J Neurol Sci. 2009;36(3):365-9.

62. Tshibanda L, Vanhaudenhuyse A, Galanaud D, Boly M, Laureys S, Puybasset L. Magnetic resonance spectroscopy and diffusion tensor imaging in coma survivors: promises and pitfalls. Prog Brain Res. 2009; 177:215-29.

63. Yuan W, Holland SK, Schmithorst VJ, et al. Diffusion tensor MR imaging reveals persistent white matter alteration after traumatic brain injury experienced during early childhood. AJNR Am J Neuroradiol. 2007;28(10):1919-25.

64. Huisman TA, Schwamm LH, Schaefer PW, et al. Diffusion tensor imaging as potential biomarker of white matter injury in diffuse axonal injury. AJNR Am J Neuroradiol. 2004;25(3):370-6.

65. Voss HU, Uluc AM, Dyke JP, et al. Possible axonal regrowth in late recovery from the minimally conscious state. J Clin Invest. 2006:116(7):2005-11 
66. Lombardi F, Taricco M, De Tanti A, Telaro E, Liberati A. Sensory stimulation of brain-injured individuals in coma or vegetative state: results of a Cochrane systematic review. Clin Rehabil. 2002;16(5):464-72.

67. Schiff ND. Modeling the minimally conscious state: measurements of brain function and therapeutic possibilities. Prog Brain Res. 2005;150:473-93.

68. Whyte J, Katz D, Long D, et al. Predictors of outcome in prolonged posttraumatic disorders of consciousness and assessment of medication effects: a multicenter study. Arch Phys Med Rehabil. 2005;86(3):453-62.

69. Brefel-Courbon C, Payoux P, Ory F, et al. Clinical and imaging evidence of zolpidem effect in hypoxic encephalopathy. Ann Neurol. 2007;62(1):102-5.

70. Canadian Medical Association. Advance directives for resuscitation and other life-saving or sustaining measures. CMAJ. 1992;146 (6):1072A-B

71. Roy DJ, Williams JR, Dickens BM. Bioethics in Canada. Scarborough, ON: Prentice Hall Canada; 1994

72. Canadian Medical Association. CMA Code of ethics (Update 2004). 2004 [cited 2010 May 13]. Available from: http://policybase. cma.ca/PolicyPDF/ PD04-06.pdf.

73. Rocker G, Dunbar S. Withholding or withdrawal of life support: the Canadian Critical Care Society position paper. J Palliat Care. 2000;16 Suppl:S53-62.

74. Singer PA, Robertson G, Roy DJ. Bioethics for clinicians: 6 . Advance care planning. CMAJ. 1996;155(12):1689-92.

75. Godlovitch G, Mitchell I, Doig CJ. Discontinuing life support in comatose patients: an example from Canadian case law. CMAJ. 2005;172(9):1172-3

76. Thompson T, Barbour R, Scwartz L. Adherence to advance directives in critical care decision making: a vignette study. $\mathrm{Br}$ Med J. 2003;327:1-7.

77. Racine E, Dion MJ, Wijman CA, Illes J, Lansberg MG. Profiles of neurological outcome prediction among intensivists. Neurocrit Care. 2009;11(3):345-52

78. Boards of directors of the Canadian Healthcare Association, Canadian Medical Association, Canadian Nurses Association, Catholic Health Association of Canada. Join statement on preventing and resolving ethical conflicts involving health care providers and persons receiving care. 1999 [cited 2010 May 13]. Available from: http://www.cna-nurses.ca/CNA/documents/ pdf/publications/prevent_resolv_ethical_conflict_e.pdf.

79. Eisenberg JB. Schiavo on the cutting edge: functional brain imaging and its impact on surrogate end-of-life decision-making. Neuroethics. 2008;1(2):75-83.

80. Beauchamp T, Childress J. Principles of biomedical ethics. 5th ed. Oxford: Oxford University Press; 2001.

81. Fins JJ. Clinical pragmatism and the care of brain damaged patients: toward a palliative neuroethics for disorders of consciousness. Prog Brain Res. 2005; 150:565-82.

82. Miller FG, Fins JJ. Protecting human subjects in brain research: a pragmatic perspective. In: Illes J, editor. Neuroethics: defining the issues in theory, practice, and policy. Oxford: Oxford University Press; 2006. p. 123-40.
83. Lennard-Jones JE. Ethical and legal aspects of clinical hydration and nutritional support. BJU Int. 2000;85(4):398-403.

84. Bacon D, Williams MA, Gordon J. Position statement on laws and regulations concerning life-sustaining treatment, including artificial nutrition and hydration, for patients lacking decisionmaking capacity. Neurology. 2007;68(14):1097-100.

85. American Academy of Neurology. Position of the American Academy of Neurology on certain aspects of the care and management of the persistent vegetative state patient. Neurology. 1989;39(1):125-6.

86. Pence GE. Comas: Karen Quinlan and Nancy Cruzan. Classic cases on medical ethics. Boston: McGraw-Hill; 2004. p. 29-57.

87. Perry JE, Churchill LR, Kirshner HS. The Terri Schiavo case: legal, ethical, and medical perspectives. Ann Intern Med. 2005;143 (10):744-8.

88. Striano P, Bifulco F, Servillo G. The saga of Eluana Englaro: another tragedy feeding the media. Intensive Care Med. 2009;35 (6):1129-31.

89. Pontifical Academy for Life and the World Medical Association of Catholic Medical Associations. Joint statement on the vegetative state. International Congress on "life sustaining treatments and vegetative state: Scientific advances and ethical dilemmas"; 2004 March 10-17; Rome; 2004 [cited 2010 May 13]. Available from: http://www.vatican.va/roman curia/pontifical_academies/ acdlife/documents/rc_pont-acd_life_doc_20040320_jointstatement-veget-state_en.html.

90. John Paul II. Address of John Paul II to the participants in the International Congress on "life-sustaining treatments and vegetative state: Scientific advances and ethical dilemmas". Vatican; 2004 [cited 2010 May 13]. Available from: http://www.vatican.va/holy_father/john_paul_ii/speeches/2004/ $\mathrm{march} /$ documents/hf_jp-ii_spe_20040320_congressfiamc_en.html.

91. Sim J. Ethical issues in the management of persistent vegetative state. Physiother Res Int. 1997;2(2):7-11.

92. Phipps E, Whyte J. Medical decision-making with persons who are minimally conscious: a commentary. Am J Phys Med Rehabil. 1999;78(1):77-82.

93. Racine E, Shevell MI. Ethics in neonatal neurology: when is enough, enough? Pediatr Neurol. 2009;40(3):147-55.

94. The Multi-Society Task Force on PVS. Medical aspects of the persistent vegetative state (2). N Engl J Med. 1994;330(22): $1572-9$.

95. Wade DT. Ethical issues in diagnosis and management of patients in the permanent vegetative state. BMJ. 2001;322(7282):352-4.

96. Jonsen AR, Siegler M, Winslade WT. Clinical ethics: a practical approach to ethical decision in clinical medicine. 4th ed. New York: McGraw Hill; 1998.

97. Fins JJ. Rethinking disorders of consciousness: new research and its implications. Hastings Cent Rep. 2005;35(2):22-4. 